УДК 625.141: 625.173

\title{
ПОВЫШЕНИЕ ЭФФЕКТИВНОСТИ ЗЕМЛЕРОЙНЫХ, СТРОИТЕЛЬНЫХ И ПУТЕВЫХ РАБОТ
}

\author{
Шаповалов Владимир Владимирович \\ д.т.н., профессор \\ Коваленко Олег Игоревич \\ Черный Владислав Игоревич \\ Нубарян Даниил Владимирович \\ Шведов Александр Юрьевич \\ ФГБОУ ВО «Ростовский государственный \\ университет путей сообщения»
}

Аннотация: статья посвящена эффективности землеройных и строительных работ. Одно из ключевых значений в повышении эффективности в таких мероприятиях играет вибрация.

Ключевые слова: грунт, вибрации, воздействие, сопротивление.

\section{IMPROVING THE EFFICIENCY OF EARTHMOVING, CONSTRUCTION AND TRACK WORK}

\author{
Shapovalov Vladimir Vladimirovich \\ Kovalenko Oleg Igorevich \\ Cherniy Vladislav Igorevich \\ Nubaryan Daniel Vladimirovich
}

\begin{abstract}
Abstrack: the article is devoted to the efficiency of earthmoving and construction works. One of the key values in increasing efficiency in such events is vibration

Key words: ground, vibration, impact, resistance.

В наше время в строительстве активно используются фундаменты из железобетонных свай. Данный тип оснований нашел свое применение в крупномасштабном и индивидуальном строительстве. Сваи устанавливаются несколькими способами: ударным, статическим, а также вибрационным.
\end{abstract}


Принцип вибропогружения свай заключается в том, что силы сцепления и трения в грунте под воздействием вибраций нужной частоты уменьшаются, и свая погружается. Скорость ее погружения увеличивается в связи с возрастанием массы вибрационной установки. Некоторыми преимуществами вышеописанного метода являются невысокая стоимость с отсутствием разрушительного воздействия на сваю, минимальные воздействия на основания близлежащих зданий и ускорение процесса работ. Необходимое количество персонала и оборудования при работах минимальны. Оборудование включает в себя копровую установку или подъёмный кран и вибропогружающий элемент, а персонал - оператора установки и копровщика.

Эксперименты по погружению в грунт элементов вибрированием состоялись впервые в 1934 году под руководством Д.Д. Барканова. Эти исследования показали высокую эффективность виброметода по сравнению с уже устаревшим на тот момент ударным. Непростым процессом считается углубление в грунт тел, подверженных вибрированию. Основной причиной уменьшения при виброметоде сопротивления грунта является снижение коэффициента его внутреннего трения при вибрации. В ходе вибропогружения вокруг сваи разрушается естественная структура грунта.

При снижении сопротивляемости грунта свая, благодаря своему весу и массе прикреплённого к ней вибропогружателя, входит в почву (Рис. 1). Эффективность данного процесса в жизни будет зависеть от факторов, среди которых масса сваи и вибропогружателя, типы грунта, количества вибрационных низкоамплитудных колебаний, которые выработаны погружателем свай (число колебаний находится в диапазоне от 400 до 2500 в минуту). Вибропогружатель (рис. 2) - это навесное оборудование, монтируемое на копровую мачту, для осуществления метода вибрационного погружения сваи сваебойной машиной. 


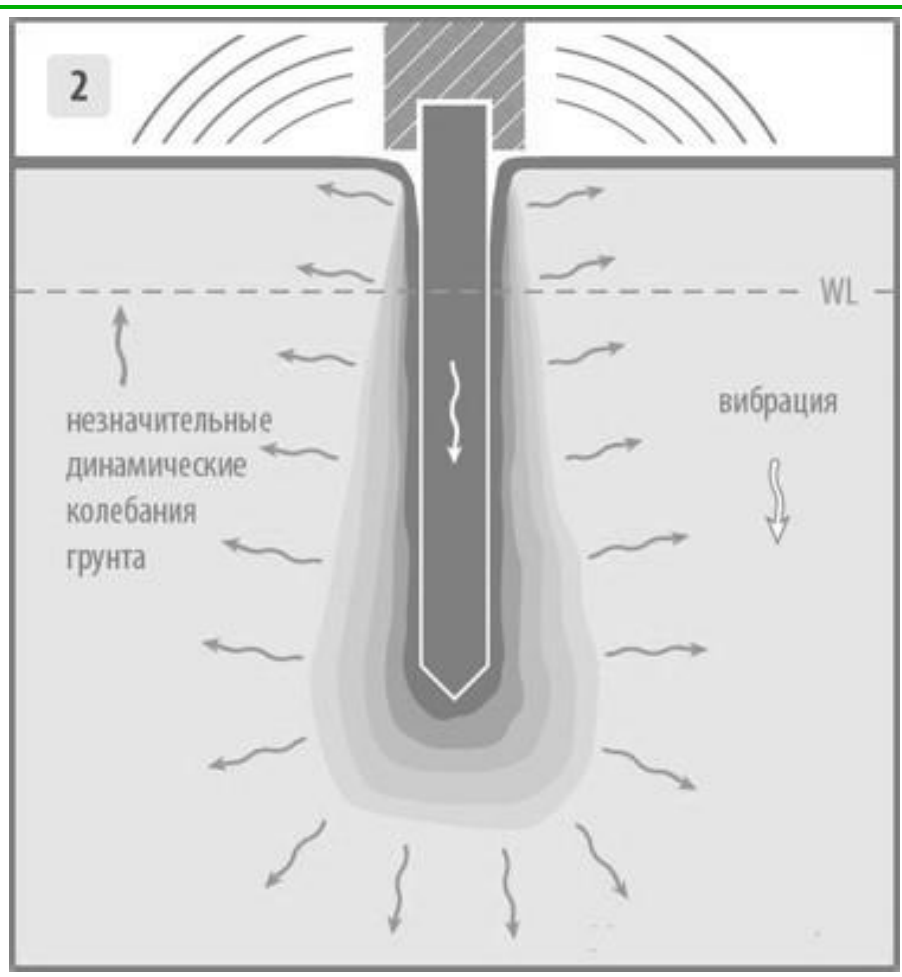

\section{Рис. 1. Процесс вибропогружения сваи}

Снижение сопротивления грунта при вибропогружении является результатом уменьшения коэффициента внутреннего трения грунта вследствие воздействия вибраций. Следует учитывать, что у грунта, находящегося в зоне погружаемой сваи, изменяется природная структура. Эти изменения зависят по большей части от структуры почвы, а именно её водонасыщенности - чем она выше, тем больше грунтовой воды притекает к месту воздействия и ослабляет связь грунтовых частиц и погружаемой сваи. Если же грунт является неводонасыщенным (глинистым или песчаным) процесс погружения будет заключаться в выдавливании сваей грунта в стороны, имеющие наименьшее сопротивление.

В связи с длительной продолжительностью зимнего сезона в определённых регионах России до 7 месяцев в году, глубина промерзания грунтов достигает $1-1,25$ м. Особенность таких грунтов заключается в повышенной прочности и увеличенному сопротивлению к разрыхлению. Коэффициент удельного сопротивления резания у талых грунтов ниже примерно в 40 раз по сравнению с мёрзлыми, а при сжатии потолок прочность почти в 20 раз. Данные параметры оказывают значительное влияние на разработку техники для работы в тяжёлых климатических условиях. Возможно применение машин, работающих в обычной среде, но с использованием модернизированных рабочих органов. 


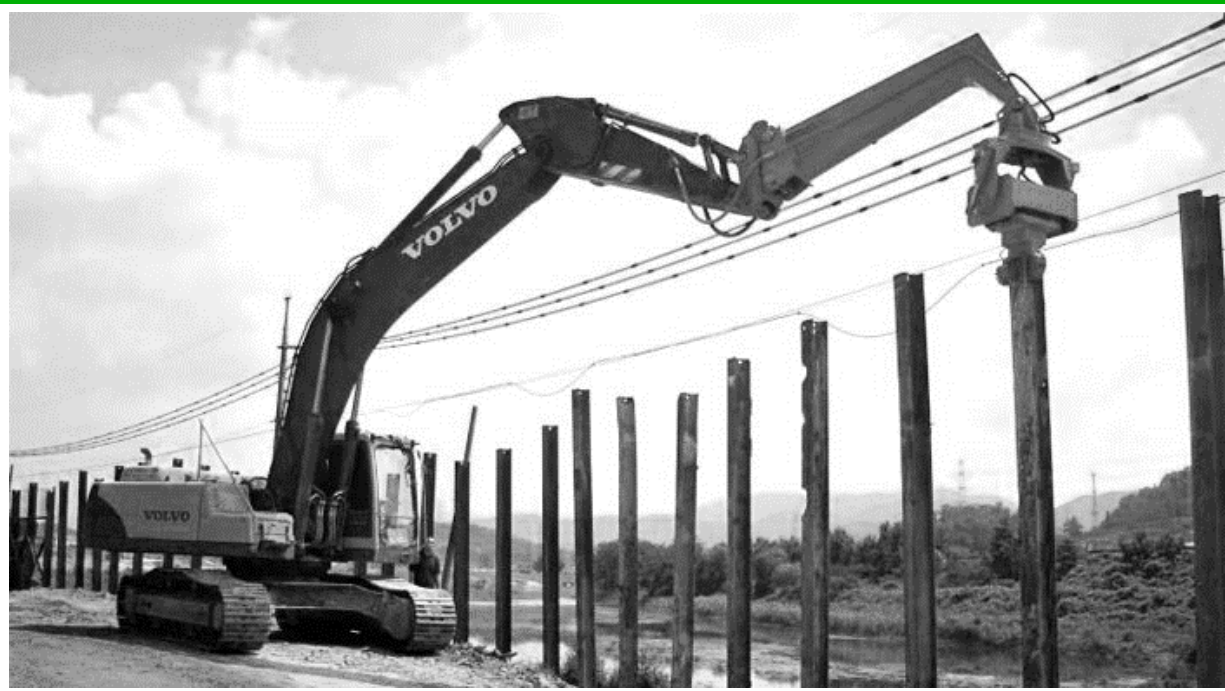

Рис. 2. Вибропогружатель

Для разрыхления замёрзших грунтов используют многоковшовые экскаваторы, бульдозеры и специальные аппараты, производящие термическое воздействие. Как правило машины имеют улучшенный рабочий орган, например, зубья вибрационного и виброударного действия. Таким образом на грунт воздействуют не только усилия ковша, но и вибрации, что, в свою очередь, повышает производительность экскаватора при работе с мерзлой почвой.

За счёт вибраций при работе вибрационных и виброударных зубьев сцепление между частицами грунта и трение ковша о грунт значительно снижаются, а значит сила, масса и мощность привода, необходимые для внедрения рабочего органа уменьшается в несколько раз! Схема модернизированного вибрационными зубьями ковша представлена на рис. 3 .
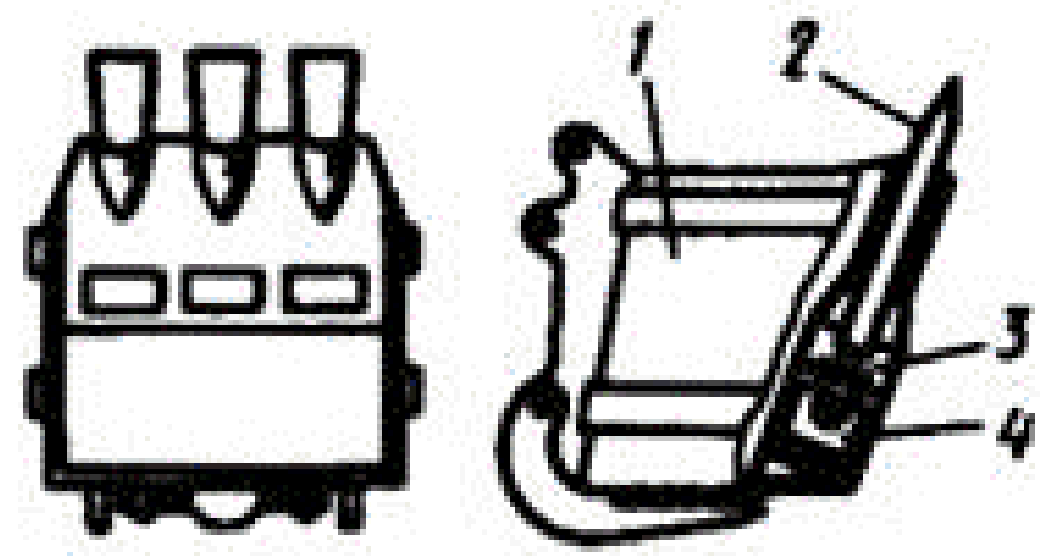

Рис. 3. Ковш экскаватора с активными зубъями

1 - ковш; 2 - зуб ковша; 3 - ударник; 4 - вибратор 
Опыт использования вибрационных механизмов, вмонтированных в ковш экскаватора, показал, что методика приносит положительные результаты. Данная техника осуществляет процесс экскавации грунта и его рыхления одновременно, а благодаря избыточному усилению резания эти машины способны послойно разрабатывать замёрзшие земляные участки.

Процессы вибрационного воздействия применяются и при создании рабочих органов железнодорожной техники, в том числе выправочноподбивочно-рихтовочных машин (Рис. 4).

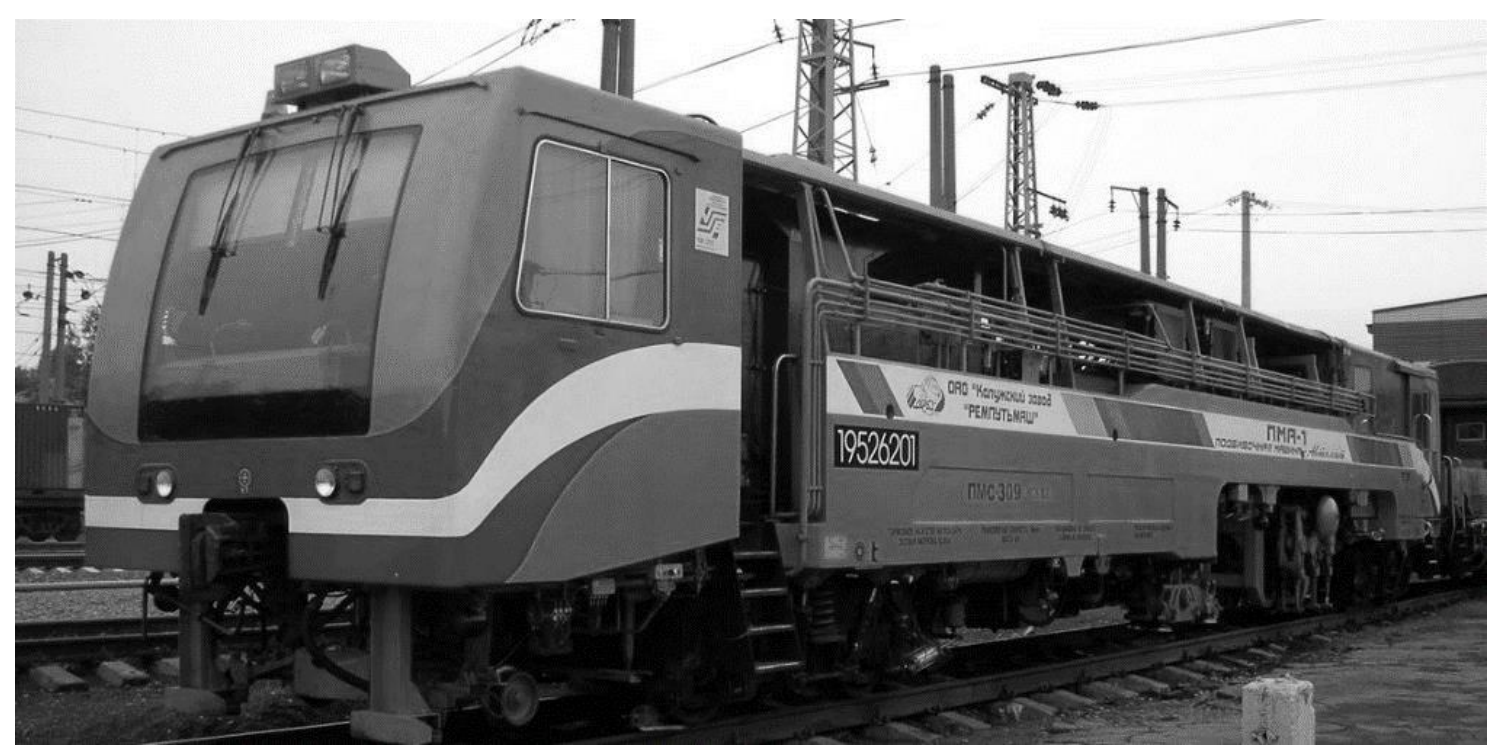

Рис. 4. Выправочно-подбивочно-рихтовочная машина ПМА-1

Машины типа ВПР бывают разными по конструкции и отличаются по функциональной направленности, но все их версии используют процесс подбивки балласта путём вибросжима. Этот метод предусматривает совершение пальцами рабочего органа гармонических колебаний частотой в 35 Гц [1], что позволяет лучше углубляться в балластную призму железнодорожного пути, тем самым обжимая и уплотняя её (Рис. 5). Вибросжим базируется на явлении резонанса колебаний между частицами балласта и воздействием рабочего органа машины.

В ходе работы подбоек возникает сопротивление, которое зависит от величины внутреннего трения в балласте. На данную характеристику влияют множество параметров, например: влажный балласт или сухой, чистый или загрязнённый и т.д. Именно снижение этого коэффициента в ходе вибрационного воздействия способствует уменьшению, в среднем, в 3-5 раз 
сопротивления внедрения рабочего органа выправочно-подбивочнорихтовочных машины в балластный слой.

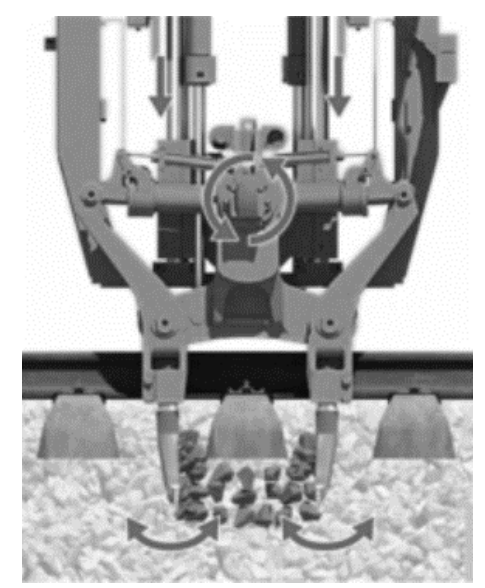

\section{Рис. 5. Процесс проникновения в балласт пути}

В заключение можно отметить, что метод вибросжима успешно используются в ходе подбивочных работ железнодорожной строительной техникой. Применение данной технологии позволило повысить качество работ, а также уменьшить энергозатраты и металлоемкость ВПР машин!

\section{Список литературы}

1. Шведов А.Ю., Повышение качества работ по виброуплотнению балласта: магистерская диссертация / А. Ю. Шведов А.Ю., В.В. Шаповалов; ФГБОУ ВПО РГУПС. - Ростов н/Д, 2016 - 95 с. - Библиогр.: с. 43.

2. Официальный сайт производителя «Plasser \& Theurer» [Электронный pecypc]. - Режим доступа: https://www.plassertheurer.com/de/home/index.html, свободный - (20.11.2020).

() В.В. Шаповалов, О.И. Коваленко, В.И. Черный, Д.В. Нубарян, А.Ю. Шведов, 2020 